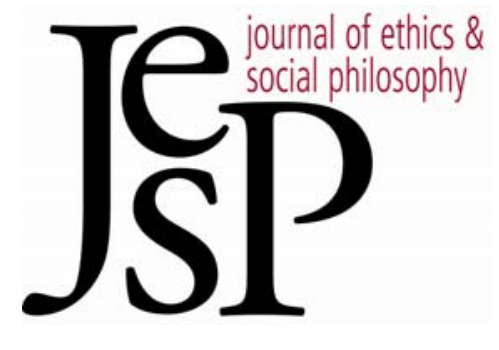

DISCUSSION NOTE

\title{
Finlay and Schroeder on Promoting a Desire
}

By JefF Behrends and Joshua DiPaolo

JoURNAL OF ETHICs \& SOCIAL PHILOSOPHY

Discussion Note | DECEMBER 2011

URL: WWW.JESP.ORG

COPYRIGHT (C) JEFF BEHRENDS AND JOSHUA DIPAOLO 2011 


\title{
Finlay and Schroeder on Promoting a Desire
}

\author{
Jeff Behrends and Joshua DiPaolo
}

\section{Promoting a Desire}

I

T IS COMMONPLACE FOR DISCUSSIONS of practical rationality to involve the idea of an action promoting a desire. The instrumental reasons that we have appear to depend somehow on which of our available actions will promote our desires or, to be more precise, the objects of our desires (Finlay 2006, 2010; Schroeder 2007). We have some instrumental reason to perform those actions that promote our desires and no instrumental reason to perform those actions that do not. Given that the promotion relation between actions and our desires' objects will partially fix which instrumental reasons we have, the analysis of that relation will have significant implications for theories of instrumental reasons, and especially for theories of practical reasons more generally that defend the Humean thesis that all normative reasons for action are analyzable in terms of the desires of agents. If it is relatively easy to promote a desire, then we will have relatively more instrumental reasons, and relatively fewer if promotion is more difficult to come by.

While promotion's role in theories of practical reasoning may seem obvious, the topic has received relatively little direct philosophical attention. That trend, however, may be coming to a close. Stephen Finlay $(2006,2010)$ and Mark Schroeder (2007) have both recently emphasized the important role that promotion plays, and have taken up the task of explaining just what promoting the object of a desire amounts to. In this paper, we aim to do three things. First, we present and explain the analyses that Finlay and Schroeder have provided. Second, we demonstrate that each account is vulnerable to counterexamples. Finally, we briefly comment on a constraint that our criticisms suggest should be applied to future accounts of promotion.

\section{Finlay's Account}

Finlay maintains that whether an agent promotes her desire through some action is a matter of whether that action renders the desire's object more likely, relative to some baseline. The baseline in question is the likelihood of the desire's object coming to pass given whatever would have happened had the agent not performed the action she in fact performs. We can put the view more clearly:

Finlay's Promotion

For some agent $\mathrm{X}$, desire $\mathrm{D}$, and action $\mathrm{A}$, A promotes $\mathrm{p}$ - the object of D - iff X's doing $\mathrm{A}$ renders $\mathrm{p}$ more likely than it would have been had $\mathrm{X}$ not done A. ${ }^{1}$

1 Finlay's (2006) discussion is actually in terms of an action being conducive to some end, but he has confirmed in personal correspondence that he takes himself to be discussing the 
So, according to Finlay, your promoting your desire is a matter of making that desire's object more likely than it would have been had you acted otherwise.

While Finlay's Promotion is capable of handling a broad range of cases, we believe that there are at least two reasons to reject it as an analysis of the promotion relation. We explain both reasons by first appealing to examples.

Buttons

Debbie has some desire. There are three buttons in front of her. If she pushes either Button A or Button B, her desire is guaranteed to be fulfilled. If she pushes button C, her desire will not be fulfilled. Debbie in fact pushes A. Had she not pushed A, though, she would have pushed B instead.

If Finlay's Promotion is true, then Debbie did not promote her desire by pushing Button A. That is because, had she not pushed A, she would have pushed B instead, which would have resulted in the satisfaction of her desire, and so pushing A did not increase the probability of her desire's object relative to whatever she would have done instead of pushing A. Intuitively, though, Debbie did promote her desire. One reason for thinking this is that Debbie performed an action that guaranteed the satisfaction her desire. It seems to us that doing something that results in the actual satisfaction of one's desire is sufficient for promoting that desire.2,3

In Buttons, we tried to demonstrate that Finlay's Promotion runs counter to intuitions about promotion itself. However, we can also cause trouble for his view by combining it with a plausible analysis of what it is to have an instrumental reason.

same topic that we are (and the same topic he discusses in his (2010), in which he actually does use the term "promotion").

2 This apparent relationship between satisfaction and promotion has also been noticed by Attila Tanyi (2011).

3 One way to respond to Buttons on behalf of Finlay is to argue that Debbie's action of pushing $A$, and her counterfactual action of pushing $B$, are really instances of the disjunctive action pushing $A$ or pushing $B$. If that were so, then we would not have presented a case in which Debbie would have acted otherwise in pushing B. We should not, of course, arbitrarily treat actions as disjunctive; some reason must be given for treating them so. We are aware of two reasons that might support taking Debbie's action to be disjunctive: that she intends to be performing the disjunctive action push $A$ or push $B$, or that she takes her reasons to push $A$ and her reasons to push B to be equally weighty. But nothing in the case suggests that we should interpret Debbie in either of these ways. If you like, simply imagine that Debbie takes herself to have some extra reason to push $\mathrm{A}$ instead of $\mathrm{B}$, which results in her having an intention to push $\mathrm{A}$ (as opposed to an intention to push $A$ or push B). As described, there would be no reason of which we are aware to treat Debbie's actual or counterfactual actions as disjunctive. Additionally, the introduction of the additional reason does not bear on whether any of Debbie's actions promote p. We are grateful to an anonymous referee for drawing our attention to potential worries involving Buttons and disjunctive actions, and to Sarah Paul for helping us to think through those worries. 
Instrumental Reason

For $\mathrm{X}$ to have an instrumental reason to $\mathrm{A}$ is for there to be some $\mathrm{p}$ such that $\mathrm{X}$ has a desire the object of which is $\mathrm{p}$, and for there to be some fact that is part of what explains why X's doing A promotes p.4,5

If both Finlay's Promotion and Instrumental Reason are true, then we would have instrumental reason to perform an action if and only if the action would render the object of one of our desires more likely than it would be if we refrained from performing that action. This combination, though, yields extremely counterintuitive results concerning what reasons Debbie has in Buttons.

Presumably, Debbie has some reason to push A. One reason for thinking this is just that pushing A would guarantee the satisfaction of one of her desires. Another reason for thinking this is that Debbie appears to have more reason to push $\mathrm{A}$ than she does to push $\mathrm{C}$. If she has more reason to push $\mathrm{A}$, though, she must have some reason to do so. However, the combination of Finlay's Promotion and Instrumental Reason leaves us with the result that Debbie had no reason to push A, because Finlay's Promotion entails that Debbie did not promote her desire by selecting A.

This second criticism is significant because one way of responding to our first objection is to simply deny that Debbie promotes her desire by pushing A. After all, one might think, it is not as if she would have lost anything in the way of desire satisfaction had she refrained from pushing A. Such a move, though, falls victim to the second objection. Debbie plainly has an instrumental reason to push A, but it is not clear how this could be explained if her pushing A does not promote any of her desires.

\section{Schroeder's Account}

Mark Schroeder has also defended the view that promoting a desire's object is a matter of making that object more likely relative to some baseline. His account differs from Finlay's only with respect to which baseline the relativ-

${ }_{4}^{4}$ This is Mark Schroeder's analysis of what it is for some fact to count as a normative reason for action. We have restricted it to an analysis of instrumental reasons because we want to avoid the problem of determining whether all normative reasons are also instrumental reasons. Our objections to Finlay's Promotion do not depend on modifying the analysis of reasons in this way.

${ }^{5}$ Of course, not everyone will take Instrumental Reason to be true. We do not mean to suggest that the principle is uncontroversial, but neither can we argue for it here. Our aim is just to show that Finlay's Promotion and (in what follows below) Schroeder's Promotion yield unintuitive results when coupled with a widely held account of instrumental reasons, and so lose credibility insofar as this account is plausible. It should be kept in mind, though, that not all of the objections we offer in this paper depend on Instrumental Reason, or any other principle of instrumental rationality, being true. Some of our objections may be successful even if Instrumental Reason is false. We are grateful to an anonymous referee for urging us to consider the import of our arguments in light of the controversial status of Instrumental Reason. 
izing is to be done. According to Schroeder, we must look not at what would have been the case had the agent not acted as she did, but instead at what would have been the case had she not acted at all. Schroeder's baseline, unlike Finlay's, does not involve the agent acting otherwise. ${ }^{6}$

Schroeder's Promotion

For some agent X, desire D and action A, A promotes $\mathrm{p}$ - the object of D - iff X's doing $\mathrm{A}$ renders $\mathrm{p}$ more likely than it would have been had $\mathrm{X}$ done nothing.

While Schroeder's account suffers from a problem that is perhaps the same as the first difficulty we raised for Finlay's, we will need to rely on a new sort of case to see why.

Buttons 2

Julie has some desire. There is one button in front of her. She knows that if she pushes the button, her desire is guaranteed to be fulfilled. However, unbeknownst to Julie, if she does not push the button, Black will ensure that her desire is fulfilled. ${ }^{7}$

If Schroeder's Promotion is true, then when Julie pushes the button in Buttons 2 she does not thereby promote her desire. However, she performs an action that guarantees the satisfaction of her desire, and for that reason we find it plausible to think that Julie pushing the button does indeed count as an instance of promotion. Notice, too, that Black's tinkerings make no difference to the actual causal sequence or to the explanation of how Julie's desire gets fulfilled when she pushes the button. We find it implausible to think that the mere presence of a counterfactual intervener could undermine promotion.

Again, though, one might find it tempting to resist our intuitions concerning cases like Buttons and Buttons 2. But even if we are wrong about the relationship between an action guaranteeing the satisfaction of a desire and it promoting the object of that desire, there are other cases that create difficulties for Schroeder's Promotion.

Do Nothing

At $t_{1}$ Austin forms the desire that $p$ be the case at $t_{3}$. Black has arranged things such that if Austin does nothing at $\mathrm{t}_{2}$, $\mathrm{p}$ will be the case at $\mathrm{t}_{3}$; Black has further arranged things such that any other behavior at $\mathrm{t}_{2}$ on Austin's part will result in not-p.

${ }^{6}$ This is so as long as doing nothing is not a way of acting otherwise. Presumably it is not, since doing nothing is not a way of acting at all.

7 As is probably clear, this case is inspired by certain kinds of cases developed by Harry Frankfurt (1969). While we admit that the intuition behind cases of this sort is not universally held, it is nonetheless widely shared. In our case, it is quite robust. After all, aside from Black's presence, Julie's pushing the button appears to be a paradigmatic case of promotion; she acts in a way that she knows will satisfy her desire. Since Black has absolutely no bearing on the actual causal sequence, it would be implausible to claim that his mere presence (and what this entails) turns a paradigmatic case of promotion into a case of nonpromotion. Surely an argument would be needed to justify this latter claim. As far as we can tell, no plausible argument is forthcoming. 
In this case, it seems obvious that Austin has an instrumental reason to do nothing at $t_{2}$. However, if Schroeder's Promotion is true, we would be unable to explain how anyone could ever have a reason to do nothing. That is because doing nothing cannot render a state of affairs more likely relative to doing nothing. Therefore, doing nothing can never, on Schroeder's account, promote a desire. And so, assuming that instrumental reasons to act or refrain from actions depend on whether such behavior promotes an agent's desire, it follows that agents can never have an instrumental reason to do nothing. Yet agents can plainly have instrumental reasons to refrain from acting. Do Nothing is an artificial case that illustrates this; there are many realworld cases that would do as well.

\section{Conclusion}

Promotion is a concept that we cannot do without, yet the two accounts on offer are problematic. Both accounts require that if doing $\mathrm{A}$ promotes $\mathrm{p}$, then doing $\mathrm{A}$ increases the probability of $\mathrm{p}$ relative to some baseline, and both accounts are subject to similar kinds of counterexamples as a result. While there are perhaps other ways of addressing these counterexamples, one way is to simply abandon the requirement that increasing the probability of $\mathrm{p}$ is necessary to promoting $\mathrm{p}$. If dropping that requirement is indeed the best way to proceed, it is a surprising result and one that indicates that the promotion relation requires much more attention than it has previously been given. This result may even suggest that promotion is best thought of nonprobabilistically. For, one might think, the central motivation for offering a probabilistic account of promotion is that, prima facie, promotion seems to require an increase in probability. Once serious doubt has been cast upon that position, though, probabilistic accounts might turn out to be unmotivated. ${ }^{8}$

Jeff Behrends

University of Wisconsin-Madison

Department of Philosophy

jbehrends@wisc.edu

Joshua DiPaolo

University of Massachusetts, Amherst

Department of Philosophy

jdipaolo@philos.umass.edu

8 This paper is part of a larger project on promotion. For helpful discussion regarding that project, and for helpful comments on this paper in particular, we would like to thank Tara DiPaolo, Stephen Finlay, Ernesto Garcia, Pete Graham, Hilary Kornblith, Chris Meacham, Sarah Paul, Gina Schouten, Mark Schroeder, Russ Shafer-Landau and Mike Titelbaum. We'd like to give special thanks to Hilary and Russ for their sagacious advice. Some of the content of this paper was also presented to audiences at the University of Wisconsin-Madison and the University of Auckland. We thank both of those audiences for helpful feedback. 


\section{References}

Finlay, Stephen (2006). "The Reasons that Matter." The Australasian Journal of Philosophy 84(1): $1-20$.

(2010). "What Ought Probably Means, and Why You Can't Detach It." Synthese 177(1): 67-89.

Frankfurt, Harry (1969). "Alternative Possibilities and Moral Responsibility." Journal of Philosophy 66: 829-39.

Schroeder, Mark (2007). Slaves of the Passions. Oxford: Oxford University Press.

Tanyi, Attila (2011). "Desires as Additional Reasons? The Case of Tie-Breaking." Philosophical Studies 152(2): 209-27. 